\section{Eosinophilic esophagitis and double-balloon enteroscopy: a dangerous combination}

A 56-year-old woman was referred for the evaluation of iron deficiency anemia. Her complaints were mild heartburn and dysphagia; she denied having abdominal pain, diarrhea, melena, or hematochezia. A previous upper gastrointestinal endoscopy had revealed erosive esophagitis and the colonoscopy was normal. Anterograde double-balloon enteroscopy (DBE) was performed (Fujinon EN-450P5/20; overtube TS-12140) and revealed erosions with fibrin in the proximal jejunum, without signs of hemorrhage. During the procedure, fresh red blood was seen over the overtube, despite the fact that we used the usual lubrication and experienced no resistance to the push of the overtube during the insertion. Biopsies of the jejunal erosions were taken and we decided to withdraw the scope. Surprisingly, two deep proximal esophageal lacerations were seen, although the endoscopic appearance of the lacerations showed no signs of perforation ( $\bullet$ Fig. 1). Proximal esophageal biopsies were taken because the mucosa adjacent to the laceration was edematous and thickened. Thoracic and cervical CT scans were done with water-soluble iodinated contrast and no perforation was seen. Histological analysis showed nonspecific jejunal erosions and eosinophilic esophagitis (25 eosinophils per high-power field).

The overall rate of complications of DBE, such as bleeding, perforation, and acute pancreatitis, has been reported to be as high as $3.4 \%$ [1]. However, complications related to the overtube have not been described before.

Eosinophilic esophagitis is a rare inflammatory disease of the esophagus and is characterized by eosinophilic infiltration (more than 15 eosinophils per high-power field on esophageal biopsies) [2,3]. Endoscopic findings are nonspecific; however, the most common finding is a linear esophageal "furrow" and esophageal rings or trachea-like appearance [3]. Food impaction is a common presenta-

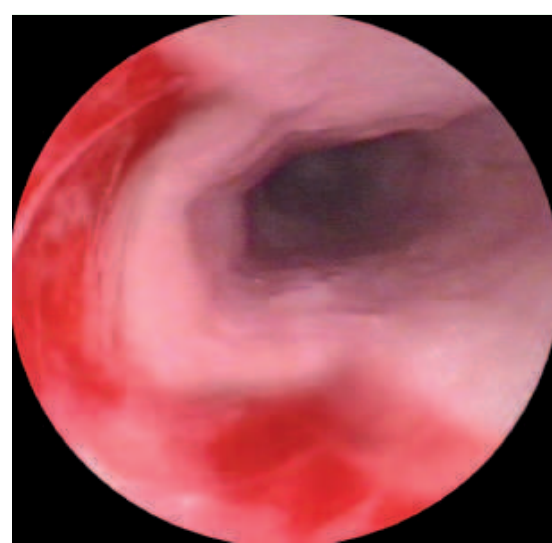

Fig. 1 Esophageal laceration after doubleballoon enteroscopy.

tion and necessitates endoscopic removal [4]. Chronic inflammation causes irreversible structural alterations of the esophagus, such as motility alteration, fibrosis, and stricture.

In conclusion, when performing DBE in patients with eosinophilic esophagitis, the possibility of esophageal perforation should be taken into account.

Endoscopy_UCTN_Code_CPL_1AI_2AD

\section{R. Kuga, C. K. Furuya jr., E. Ide,}

E. R. Baba, S. E. Matuguma, S. S. Ueda,

\section{S. Ishioka, P. Sakai}

Gastrointestinal Endoscopy Unit, Department of Gastroenterology, São Paulo University Medical School, São Paulo, Brazil

\section{References}

1 May A. Current status of double balloon enteroscopy with focus on the Wiesbaden results. Gastrointest Endosc 2007; 66 (Suppl): $\mathrm{S} 12-\mathrm{S} 14$

2 Prasad GA, Talley NJ. Eosinophilic esophagitis in adults. Gastroenterol Clin North Am 2008; 37: 349- 368

3 Johnson DA. Eosinophilic esophagitis. Clinical Update 2006; 14: 1 - 3

4 Straumann A, Bussmann C, Zuber M et al. Eosinophilic esophagitis: analysis of food impaction and perforation in 251 adolescent and adult patients. Clin Gastroenterol Hepatol 2008; 6: 598-600
Bibliography

DOI $10.1055 / s-0029-1214489$

Endoscopy 2009; 41: E85

(c) Georg Thieme Verlag KG Stuttgart · New York . ISSN 0013-726X

Corresponding author

\section{R. Kuga, MD}

Rua Cincinato Braga, 37 - cj. 12

01333-011

São Paulo - SP

Brazil

Fax: +55-11-32850026

rogeriokuga@yahoo.com.br 